\section{Andrew Berger}

is the VP International for

Alien Technology. He is leading

Alien's commitment to building

a significant market presence in

international markets. Andrew

was previously an equity

partner at Accenture. He left

Accenture following their

successful IPO in July 2001 to

pursue more entrepreneurial activities. Andrew is a supply

chain specialist and has

published two supply chain

books. He is a regular speaker

at RFID and supply chain

conferences.
Keywords: RFID, supply chain, marketing, EPCGlobal, EPC Class 1

\title{
New Technology Briefing
Radio frequency identification
}

\author{
Andrew Berger \\ Received (in revised form): 15 January 2005
}

\begin{abstract}
In every business cycle there are new technologies that promise to change the way in which major businesses operate internally and within their ecosystems. In the 1990s the internet was one of those technologies, but few who saw its early iterations could have predicted the scale of its impact. Most major businesses missed the initial opportunities of the internet because they failed to recognise its relevance and potential. RFID technology has the potential to be an even more disruptive technology than the internet. But it is not yet easy for most business managers to understand the far-reaching implications of RFID solutions. Few could have predicted that, by 2004, there would be over 750 million users of the internet and over 4.3 billion webpages. RFID technology has the potential to add between 100 billion and 1 trillion tags or 'wireless network computers' to business networks and the internet during this business cycle. This New Technology Briefing looks at the key implications of RFID for businesses over the next few years. It tries to explain why some of the world's largest organisations and RFID technology vendors have been pushing ahead aggressively with implementing a massive extension to current internet technologies. It helps to explain why, in a world of billions of things, ultra low cost and high performance are critical.
\end{abstract}

\section{What is RFID? Why is it important?}

Radio frequency identification (RFID) is an old technology with new potential. Invented towards the end of the Second World War, it is a way of using energy from radio waves to receive simple information packets back from either passive or active (battery-powered) RFID tags. Like the fax machine (which was invented in 1922), it is a technology that has been waiting for its time.

One of the best ways to think about RFID is to think about a mirror reflecting the sun. The radio (the sun) transmits power, the RFID tag (the mirror) is a passive receiver that use the power of the transmitter to return a signal (a focused beam of information). In the case of passive RFID tags this means that a tag can 'shout back' its unique serial number over a distance of about three to five metres.

So what? There are three main implications from this simple capability that will make a huge difference over existing bar-code technology: 
allowing supply chain visibility and asset tracking

- long-range interrogation of tags means that it is possible to monitor tags in more locations and without human involvement

- real-time visibility and network connectivity offers the ability to 'do something about' the information in real time.

\section{New capabilities}

\section{Strong business case for retailers}

In future, these three new capabilities will give us new levels of insight into some important questions.

- Where are our products and assets?

- What is and is not working (eg stockouts, leakage, missing assets, inventory levels)?

- What could we change to work better, in real time?

New investments (probably over $\$ 300 \mathrm{~m}$ by the end of 2005) and developments in business processes and technology have created the opportunity for RFID to be an exponential extension of internet technologies. While the internet was about connecting people electronically, RFID is about enabling products or things to connect to each other. The 'thing-to-thing thing' is in its early days, but its potential is creating huge excitement in both traditional companies like Wal-Mart and Gillette and VC-backed start-ups like Alien Technology.

Many of the major companies that are implementing RFID are reluctant to discuss their programmes with outsiders because they see this work as the next source of competitive advantage. As a result many of the presentations at conferences concern projects that are 12-18 months old. Much more is happening behind closed doors. The lack of visibility of major projects should not be taken as a cause for complacency - lots of learning is already taking place and benefits delivered

For instance, some major retailers are seeing the opportunity to eliminate manual scanning of the billions of cases and pallets that they move each year. RFID allows automatic scanning at a distance and without manual interference. Other retailers see RFID as an excellent means to secure the high-value goods in their supply chain and significantly to reduce worrying levels of leakage and theft. Gillette's RFID initiatives are driven by a realisation that there is a huge opportunity to increase revenue by avoiding out-of-stock (OOS) situations. They are also aware that they have two of the most 'leaked' products in retailers - Mach 2 razors and Duracell batteries.

In addition, we are seeing RFID pilots in airports, consumer electronics, medical, pharmaceutical, automotive, packaging, aerospace and defence applications. We are seeing pilots in all regions, including countries such as the USA, Korea, Japan, Germany, France, the UK, Austria, Australia, Israel, Singapore and Thailand. There are few CEOs or management boards that have not now asked the question: 'What are we doing about RFID?' 


\section{RFID data protection and privacy}

There has been a great deal written on the privacy implications of RFID some well informed, some exaggerated and some distinctly uninformed. However, this has been a strong 'wake up' call to the industry and end users to put in place the right guidelines for usage of RFID and privacy protection, long before the mass roll out of this technology. This is a good thing - the relevant agencies have highlighted their concerns and the industry is responding rapidly. The response is centred around three rights for consumers: the right to know that goods are tagged, the right to kill the tag if desired and the right to know that no personal data can be associated with the tag without permission. The European Union recently issued a Working Paper, Article 29 on RFID and Data Protection. This paper sets out to provide guidance to RFID deployers and to help RFID manufacturers to carry out their obligations under the EU data protection Directive. The industry is acutely aware of the danger of scare headlines such as 'Spy tags'. Under EPC Global the industry has recognised the issue and developed a consumer friendly response. The message for marketers is to understand the guidelines and the correct approach to privacy friendly RFID applications.

\section{Why is RFID expanding so fast now?}

There was no point trying to connect billions of products before we had the business systems and the network connectivity to manage the information. During the 1980s and 1990s huge investments in global business systems and connectivity have created this infrastructure. In effect, big business has built 'new houses' and 'plumbed and wired the infrastructure'. What was missing were the 'switches, the sensors and the sinks' that will make all this infrastructure truly useful and valuable.

The current situation is not dissimilar to the early days of supermarket checkout scanners. In the late 1980s we worried about consumer acceptance of bar-code scanning and the reliability of laser scanners. Within a few years we were more concerned about what to do with the data. The leading retailers of the world today developed the strongest IT capabilities and exploited them consistently and ruthlessly. They quickly understood the value of data and the expansion opportunities that market knowledge could create.

The leading retailers and consumer goods companies also recognised that there is a huge business case for rolling out RFID if the costs of tags could be reduced to about five cents per tag. Their problem was that the incumbent RFID technology providers were targeting 50 cents to one dollar and seeking to make high gross margins from sales of silicon chips. The master stroke was the development of EPCGlobal as a user-driven standards body with an absolute focus on ultra-low-cost, high-performing RFID solutions. EPCGlobal (through its early version, the AutoID

\section{Growth through} agreed standards
Centre) created huge interest and investment in UHF RFID through its development of EPC Class 1 Generation 1 and Class 0 standards. This has created a huge 'bow-wave' of support for new RFID solutions throughout 
an extended ecosystem of tags, readers, antennas, middleware, printers, handheld scanners and IT systems providers.

\section{Delivering the five cent tag}

An RFID tag is made up of five key elements:

— an integrated circuit (IC)

- a tag antenna

- packaging to connect the IC to the antenna

- a process for connecting the IC to the antenna

- adhesive for attaching the tag into a label.

\section{Critical cost factors}

If a tag is to cost five cents, each of these elements has to cost less than one cent. You cannot start with a 15 cent IC and end up with volume production of a five cent tag. The challenge has been about how to bring ultra high volume, low cost and performance together consistently.

There have been three big breakthroughs on the five cent tag:

- a clear message from customers that this is the maximum long-term price

- new process technology (such as Alien's fluidic self-assembly (FSA) process) that makes the five cent tag a realistic goal for 2007 (at volumes of 10 billion units)

- the development of ultra-high-speed roll-to-roll processes for RFID tag production.

These breakthroughs have sent a shockwave of economic reality through the technology vendor community. There is now a clear realisation that RFID will be a key enabling technology of the next business cycle. Symbol's recent $\$ 230 \mathrm{~m}$ acquisition of Matrics is an early sign of the potential of this market.

\section{Start small, grow fast}

\section{Where to start? Where to focus?}

It is easy to talk to RFID specialists and to attend RFID conferences. It is more difficult to make real and useful progress - particularly since new EPCGlobal standards and ISO standards for UHF RFID are still work in progress. The new EPC Class 1 Gen 2 standards promise much but will take time to deliver. Some areas where companies can already move forward are:

- appoint a full-time project manager and team

- focus on a small number of real ROI opportunities

- talk to the pioneer companies like Gillette, Wal-Mart and the US Department of Defense about their learnings

- get real experience through pilots

- plan the future rollouts

- work with RFID partners that have deep but relevant expertise. 
New marketing opportunities

\section{Dive in now}

\section{What comes next for marketers?}

RFID is currently the domain of technologists, IT professionals and supply chain futurists. It is not much different to the early days of barcode scanning. But RFID offers much more future potential for marketers. Consider five simple questions as a marketer.

- What would we do differently if we knew exactly where all our current products were in the supply chain?

- How would we manage promotions if we could have an accurate daily feedback on changes to customer demand?

- How would we increase manufacturing flexibility to meet real data on real demand?

- What would we do if we could accurately track counterfeiting of our products and leakage in our internal supply chain?

- How could we respond responsibly to this opportunity without provoking a backlash around consumer privacy?

The most interesting thing for marketers is the potential of RFID to give them real-time information on their products and the impact of their marketing efforts. The challenge is to understand what you will do differently with these data before your competitor learns. The largest initial impact is likely to be in the planning area, where guesswork and forecasts will be replaced by real-time decision making. The role of product and production planners will change. A forecast of the near future is that there will be far fewer but much smarter planners in most major companies over the next five to seven years.

\section{Summary}

RFID technology will be the logical extension to the information and communications technology developments of the 1990s. It has the potential to create a vast extension to company networks and the internet by connecting 'things to things' and enabling people to make smarter real-time decisions. There is still a lot to learn and do around RFID, but the basic building blocks are already in place. 